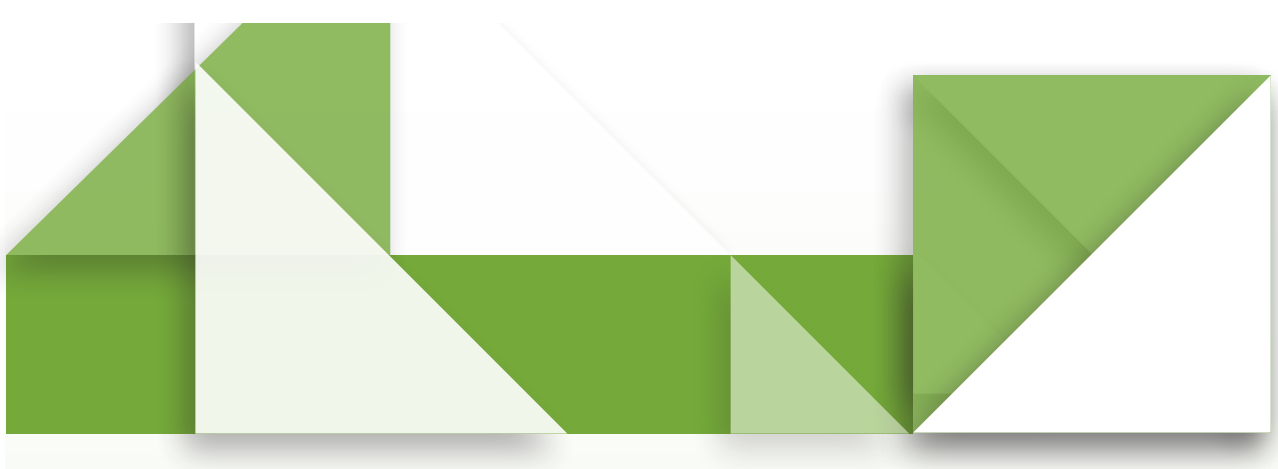

\title{
Um estudo sobre formação 1 continuada para professores de matemática da escola básica
}

\section{- A study of continuing education for teachers of Elementary School mathematics}

- Un estudio sobre la formación continua para profesores de matemática de la escuela básica

\section{Resumo}

Este artigo apresenta uma análise de cursos de formação continuada oferecidos a professores da Educação Básica na área da Educação Matemática. Nesses, foram explorados conteúdos matemáticos, bem como o uso da calculadora e da estimativa. Embora um grupo de pesquisadoras iniciasse as discussões nos encontros, os docentes participantes opinavam sobre a viabilidade e produtividade das atividades e foram desafiados a desenvolver, com seus estudantes, no mínimo, duas delas e descrever os resultados em um relatório. A análise do material - relatórios e gravação dos encontros - apontaram que as atividades mais desenvolvidas foram referentes à estimativa e ao uso da calculadora. Ademais, os espaços proporcionados à reflexão e troca de experiências foram, segundo os participantes, importantes para a mudança da prática pedagógica.

\section{Marli Teresinha Quartieri* leda Maria Giongo* Márcia Jussara Hepp Rehfeldt ${ }^{* * *}$ \\ Alessandra Corbellini**** Carolina Bianchini***** \\ rit}

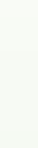




\section{Resumen}

Este artículo presenta un análisis de cursos de formación continua ofrecidos a profesores de educación básica en el área de Educación Matemática. En estos, se exploraron contenidos matemáticos, así como el uso de la calculadora y estimativa. Aunque un grupo de investigadoras iniciase las discusiones en los encuentros, los profesores participantes opinaban sobre la viabilidad y la productividad de las actividades y fueran desafiados a desarrollar, con sus estudiantes, al menos dos de ellas y describir los resultados en un informe. El análisis del material - informes y grabación de los encuentros - señalaron que las actividades más desarrolladas fueran referentes al estimativa y el uso de la calculadora. Además, los espacios proporcionados para la reflexión y cambio de experiencias fueron, según los participantes, importantes para el cambio de la práctica pedagógica.

Palabras clave:

Formación

continua. Práctica

Pedagógica.

Cambio de

experiencias.

Motivación.

Reflexión. 


\section{A temática e a abordagem teórica}

A temática formação de professores tem sido amplamente discutida em distintos referenciais teóricos. Para Mossmann (2005) a formação continuada deveria ser uma ação contínua e conjunta entre professores e docentes formadores por meio de encontros, cursos, compartilhamento de experiências, produção de conhecimento e reflexões teóricas e práticas num processo ininterrupto e não somente em momentos e ações pontuais e isoladas do processo pedagógico. Romanowski (2006) destaca que o eixo central dos programas de formação continuada está na prática dos docentes e nos problemas oriundos dessa. Ainda de acordo com a autora, a formação desenvolvida por meio de cursos ofertados pelas instituições de ensino superior pode ser vista como uma possibilidade de aprendizado pelos professores participantes. "Portanto, os programas de formação continuada precisam incluir saberes científicos, críticos, didáticos, relacionais, saber-fazer pedagógico e de gestão" (Romanowski, 2006, p. 133).

Especificamente em relação à Educação Matemática, Santos (2011) comenta que a formação continuada pode auxiliar para a melhoria dos processos de ensino e de aprendizagem, ao desenvolver ações que favoreçam reflexões e mudanças na forma de conceber a Matemática e nos processos de ensinar e de aprender conteúdos relativos a essa disciplina. Além disso, pode proporcionar reflexão para além da prática de sala de aula, envolvendo aspectos da profissionalização docente. Nessa perspectiva, Guérios (2002, p. 14) destaca que:

[...] quem vivencia a prática docente sabe que ela é dinâmica, complexa e imprevisível, sendo atravessada pela subjetividade de quem a produz. Cada nova ação, cada experiência demanda o desenvolvimento de uma prática decorrente das circunstâncias e dos sujeitos que dela participam. E, de acordo com nosso modo de entender a evolução do professor em sua prática pedagógica, é nesse processo que o professor produz seus saberes, ao se constituir profissionalmente.

Concordamos com as posições de Santos (201 1) e Guérios (2002) no que se refere ao dinamismo e à complexidade presentes no ato de proporcionar formação continuada para professores que atuam nas mais diversas redes e modalidades de ensino. Cientes disso optamos por ofertar cursos que proporcionassem aos professores da Educação Básica processos dinâmicos de formação, com momentos de reflexão sobre as teorias e as práticas em Educação Matemática, compostas por várias atividades planejadas e organizadas, tais como: leituras individuais e em grupo, problematização de atividades, compartilhamento de experiências, num processo contínuo de discussão e reflexão sobre o ensinar e o aprender Matemática.

Nesse sentido, o estudo aqui apresentado tem por objetivo relatar resultados advindos de discussões ocorridas no decorrer de três cursos de formação continuada, destinados a professores da Educação Básica, os quais ocorreram no Centro Universitário Univates, Lajeado-RS-Brasil, com o propósito de problematizar o ensino e a aprendizagem da Matemática. Tal ação está vinculada à pesquisa denominada "Ciências Exatas da Escola Básica ao Ensino Superior", que tem como meta discutir, junto a professores da Educação Básica, o currículo das disciplinas de Matemática, Química e Física. A seguir, evidenciamos a sistemática de realização desses cursos, bem como algumas atividades realizadas e resultados emergentes.

\section{A sistemática dos cursos ofertados}

No decorrer de 2010 e 2011 , ofertamos três cursos de formação continuada com a mesma 
sistemática: quarenta horas divididas em oito encontros presenciais e dois à distância. Dessa forma, em sábados intercalados, problematizamos, junto a um grupo de professores da Educação Básica, conteúdos e metodologias vinculados à disciplina Matemática. Nos encontros presenciais, disponibilizamos aos participantes textos e atividades referentes aos temas em estudo, as quais eram respondidas. Além disso, discutimos possibilidades e limitações de incorporar, na prática pedagógica dos docentes participantes, tais atividades que, após analisadas coletivamente, eram passíveis de reorganização e reestruturação.

No primeiro encontro de cada curso, combinamos com os participantes que cada um deveria desenvolver, nas turmas em que atuava, no mínimo, duas atividades exploradas coletivamente. Aliados à efetivação destas, tinham a tarefa de produzir um relatório, especificando-as, bem como as dificuldades, avanços e propostas de continuidade a serem entregues no último encontro. Neste, além da entrega dos relatórios, ocorreria a socialização das tarefas desenvolvidas. Este momento tinha o intuito de os participantes discutirem a análise dos resultados encontrados, bem como sugerir alterações nas atividades e na metodologia. As discussões dos encontros foram gravadas e transcritas.

A seguir, apresentamos a descrição dos conteúdos problematizados, bem como algumas das atividades ${ }^{1}$ de cada um dos três cursos ofertados:

a) Curso Problematizando a Matemática nos Anos Iniciais do Ensino Fundamental oferecido em 2011 . Neste, fizeram-se presentes vinte e dois professores dos Anos Iniciais do Ensino Fundamental, dos quais a maioria trabalhava em escola da rede municipal de ensino. Os temas discutidos se constituíram em estimativa, uso da calculadora, operações elementares, geometria espacial, simetria.

No encontro envolvendo a estimativa foram contempladas medidas de comprimento, de área, de volume, de quantidade, de capacidade. Os professores respondiam questões estimando valores, bem como descrevendo a estratégia utilizada. A discussão realizada, após as atividades, propiciou-lhes a oportunidade de ter contato com outras práticas. A seguir um exemplo de atividade que exploramos:

Responder "rapidinho":

a. Na sala, há mais ou menos de 18 pessoas?

b. Você já viveu mais ou menos que 8000 dias?

c. A superfície do quadro tem mais ou menos de $4 \mathrm{~m}^{2}$ ?

d. Seu pé mede mais ou menos de $25 \mathrm{~cm}$ ?

e. A sala tem mais ou menos de $11 \mathrm{~m}$ de comprimento?

f. A medida do umbigo até os pés é de mais ou menos de $1 \mathrm{~m}$ ?

Não apresentaremos neste artigo todas as atividades propostas nos referidos cursos em função da limitação de laudas. Optamos, assim, por descrever aleatoriamente apenas algumas delas. 
g. A circunferência do seu pescoço mede mais ou menos de $30 \mathrm{~cm}$ ?

h. A reta desenhada no quadro tem mais ou menos de $40 \mathrm{~cm}$ ?

i. Nessa sala, há mais ou menos de 900 lajotas inteiras?

i. Tudo o que você leu até aqui tem mais ou menos de 420 letras?

FONTE: Das autoras

Nessa atividade, os professores tinham apenas um minuto para responder às questões. Após a estimativa das respostas, os valores foram por eles comprovados por meio de medidas realizadas com instrumentos de medida específicos, em cada caso. No final, foi realizado um levantamento de quanto cada um acertou. $\bigcirc$ número foi de, aproximadamente, $45 \%$, o que demonstra que os próprios docentes tinham dificuldades em estimar valores. Assim, optamos por explorar, durante os demais encontros, sempre que possível, atividades envolvendo estimativas e os temas de estudo propostos.

No segundo encontro, problematizamos o emprego da calculadora nos Anos Iniciais, questionando a pertinência de seu uso. Observamos que a maioria dos presentes, inicialmente, posicionou-se contra a inserção desse artefato em suas práticas pedagógicas. Entretanto, após as atividades apresentadas, alguns professores concluíram que essa ferramenta pode ser usada nos Anos Iniciais, porém, como bem apontou um deles, "em alguns momentos como ferramenta de ensino para fazer os alunos pensarem" (P4)2.

No terceiro encontro, desenvolvemos tarefas envolvendo as operações elementares (adição, subtração, divisão e multiplicação), priorizando-se situações-problema. Durante essa atividade, as discussões foram produtivas em relação às formas de realizar as opera-

2 Os relatórios entregues foram enumerados por P1, P2, P3, . identificando desta forma os professores participantes. Cabe destacar que foram recebidos sessenta relatórios dos três cursos oferecidos. ções. No quarto encontro, problematizamos atividades envolvendo a geometria espacial, em particular, a construção de sólidos, usando cubinhos. No quinto, realizamos atividades relacionadas à simetria, utilizando dobraduras, recortes, espelhos e papel quadriculado. No sexto, os participantes resolveram várias atividades envolvendo simetria, as quais foram discutidas e analisadas.

No sétimo houve a participação de uma aluna do Mestrado Profissional em Ciências Exatas da Instituição explanando sobre sua dissertação relacionada aos Anos Iniciais. No oitavo encontro, houve a apresentação e socialização das atividades que os participantes realizaram durante o período do curso.

b) Curso Problematizando a Matemática nos Anos Finais do Ensino Fundamental Módulo I" - oferecido em 2010. Participaram vinte professores de Matemática, os quais ministravam aulas da $5^{a}$ série $/ 6^{\circ}$ ano até $8^{a}$. série/9. ano do Ensino Fundamental. Os temas abordados tiveram como foco o ensino da geometria e da álgebra.

No primeiro encontro, disponibilizamos um texto sobre as concepções da álgebra, o qual foi discutido e problematizado. Em seguida, realizamos uma atividade que tinha por objetivo calcular o perímetro de uma folha retangular, utilizando tiras de cores e tamanhos diferentes. As respostas deveriam ser representadas algebricamente e, ao final, calcular o valor numérico das expressões encontradas.

No segundo encontro discutimos atividades relacionadas à sequências. No terceiro 
utilizamos os seguintes materiais: seis peças quadradas, medindo cada uma $12 \mathrm{~cm}$ de lado; quinze peças retangulares, com $12 \mathrm{~cm}$ por $2 \mathrm{~cm}$ de lado por unidade e vinte e quatro peças de forma quadrada com $2 \mathrm{~cm}$ de lado. Com isso realizamos atividades para introduzir produtos notáveis e fatoração. Seguem alguns exemplos:

1) Para esta atividade considerar o lado do quadrado maior " $x$ " e o lado do quadrado menor "1". Construir retângulos ou quadrados que satisfaçam as expressões algébricas a seguir. Em cada caso, escrever a medida da base e da altura do retângulo ou do quadrado resultante ${ }^{3}$ :
a. $x^{2}+4 x$
b. $x^{2}+8 x+16$
c. $x^{2}+5 x+4$
d. $x^{2}+14 x+20$

2) Analisando os dados obtidos no exercício anterior, o que podemos concluir, sobre:
a. $a x^{2}+b x$
b. $a x^{2}+b x+c$

FONTE: das autoras

No quarto encontro, inicialmente, exploramos mais algumas atividades referentes aos produtos notáveis. Após, discutimos problemas envolvendo geometria e álgebra. No quinto, continuamos a discussão da álgebra; entretanto, com o foco na resolução de problemas. No sexto e sétimo encontros, desenvolvemos atividades envolvendo fractais. Por fim, no oitavo, ocorreu a apresentação e socialização das atividades que os participantes realizaram durante o curso.

c) Curso Problematizando a Matemática nos Anos Finais do Ensino Fundamental - Módulo Il - oferecido em 2011 . Neste curso tivemos a participação de vinte e cinco professores de Matemática dos Anos Finais do Ensino Fundamental e do Ensino Médio. Contemplamos o uso da calculadora e os conteúdos de proporcionalidade e de trigonometria no triângulo retângulo.

No primeiro e segundo encontros, problematizamos o uso da calculadora. Como mencionado anteriormente, também neste curso alguns professores manifestaram-se desfavoravelmente, enquanto outros argumentaram que ela deveria ser utilizada em algumas aulas, dependendo do objetivo do professor. Os participantes, inicialmente, fizeram as atividades disponibilizadas e, logo após, discutimos o objetivo de cada atividade, bem como em que série/ano poderiam ser efetivadas. Destacamos o seguinte exemplo de atividade ${ }^{4}$ :

Por questão de espaço, apresentamos apenas alguns exemplos de atividades. Cabe salientar que foram apresentadas aos participantes várias expressões.

4 Mais atividades estão disponibilizadas em http://www.univates.br/ppgece/materiais-didaticos/2011 
Acionar a sequência de teclas indicadas e escreva o que ocorre em cada caso:
a. $8+3======$
c. $3+=====$
e. $6-=====$
g. $4 \times 5======$
i. $2 y^{\times} 3==$

b. $3+8======$

d. $50-4=====$

f. $5 \times 4======$

h. $2: 10====$

FONTE: Das autoras

No terceiro encontro, realizamos experimentos e atividades para verificar situações que apresentassem ou não proporcionalidade direta e inversa e, no quarto, continuamos a problematização de ambas. Além disso, exploramos a resolução de problemas que envolvessem proporcionalidade por meio de tabelas e gráficos. No quinto usamos o método de redução à unidade para resolver situações envolvendo regra de três simples e composta. Os professores apresentaram algumas dificuldades, principalmente com relação à regra de três composta, pois sempre procuravam resolver as situações por meio do algoritmo padrão.

No sexto e sétimo encontros, o foco foi o ensino da trigonometria no triângulo retângulo. Inicialmente, percorremos alguns pontos da Instituição para que estimassem o valor do ângulo de inclinação dos locais solicitados. Outra atividade desenvolvida foi a construção do astrolábio para medir alturas de alguns pontos determinados. Na sequência, discutimos e analisamos problemas envolvendo seno, cosseno e tangente. $O$ oitavo encontro iniciou com o relato de uma aluna do curso de Mestrado Profissional em Ciências Exatas que desenvolveu seu trabalho com foco na trigonometria do triângulo retângulo. A referida mestranda expôs algumas de suas atividades realizadas em sua prática pedagógica investigativa. No final, os participantes socializaram atividades desenvolvidas, bem como comentaram pontos positivos e outros a serem melhorados.

A seguir, apresentamos a análise dos relatórios dos professores e das apresentações do último encontro dos cursos de formação continuada ministrados.

\section{Alguns resultados da análise dos relatórios}

Como frisado anteriormente, no último encontro presencial, nos três cursos, os participantes entregaram um relatório descrevendo, no mínimo, duas atividades que foram exploradas em sala de aula com suas turmas. Ademais, anexaram fotos da prática pedagógica e excertos de trabalhos realizados pelos alunos.

Quanto aos temas abordados nos cursos e que foram aplicados pelos professores em suas aulas, podemos destacar que:

a) Nos Anos Iniciais do Ensino Fundamental, todas as atividades foram realizadas; algumas, entretanto, em maior número, tais como: $90 \%$ dos participantes exploraram as atividades relacionadas à estimativa, $50 \%$, ao uso da calculadora e $40 \%{ }^{5}$, atividades usando simetria, em particular, as com dobradura.

b) Nos Anos Finais do Ensino Fundamental - módulo I-, foram exploradas as atividades

Cabe destacar que,como cada participante realizou pelo menos duas atividades, o total não será 100\%. 
envolvendo sequência por $70 \%$ dos participantes; o uso do material concreto para introduzir fatoração, por 40\%; atividade de introdução à Álgebra que envolvia valor numérico, por $20 \%$. Foram citadas a construção de fractais e o uso da Torre de Hanói.

c) Nos Anos Finais do Ensino Fundamental - módulo II -, as atividades envolvendo o uso da calculadora foram citadas por $70 \%$ dos participantes; os problemas de regra de três por redução à unidade por 60\%; o uso do astrolábio foi mencionado por $20 \%$.

Por meio desse levantamento, podemos inferir que as atividades que envolveram a calculadora foram as mais exploradas, embora, inicialmente, alguns docentes participantes tivessem receio em utilizá-la. Destacamos alguns comentários destes nos momentos de socialização e descritos nos relatórios ${ }^{6}$.

andamento da atividade [referindo-se às atividades com o uso da calculadora] foi muito tranquilo, pois despertou o interesse em aprender e buscar novas alternativas para a resolução dos exercícios propostos. Para desenvolver essa atividade utilizei o material fornecido e funcionou muito bem, com uma ótima aceitação e questionamentos sobre quando a atividade retornaria. (P1)

Acredito válida a atividade com o uso da calculadora, pois ela exigia do aluno refletir, fazer tentativas, o raciocínio lógico, enfim, várias habilidades matemáticas. Desta forma, o professor deve propor atividades que desafiem os estudantes, pois somente assim eles farão um bom uso da calculadora. (P28)

Os alunos demonstraram uma enorme euforia, todos calculavam, observavam as calculadoras dos colegas, perguntavam se iríamos fazer continhas com elas, enfim muitas perguntas. [...] foi realmente uma atividade prazerosa, pois todos me surpreenderam com seus raciocínios rápidos. (P29)

Os excertos acima evidenciam o entusiasmo dos professores diante do interesse e motivação de seus alunos em relação às atividades propostas com a utilização da calculadora. Tal posição está em consonância com os Parâmetros Curriculares Nacionais (Brasil, 1998) que expressam que essa ferramenta pode ser usada como um recurso para potencializar a aprendizagem de conteúdos matemáticos na medida em que favorece a busca e percepção de regularidades e o desenvolvimento de estratégias para resolução de situações-problema, uma vez que os alunos ganham tempo na execução dos cálculos.

Cabe também pontuar o quanto as atividades envolvendo estimativa foram exploradas pelos professores dos Anos Iniciais. E, como aponta Machado (2010, p. 10), o ensino da Matemática "deve levar o aluno a organizar o pensamento e analisar criticamente informações e dados, ou seja, a Matemática não deve se limitar ao saber fazer contas, mas ao saber estruturar situações, analisá-las, 
fazer estimativas, ter um raciocínio próprio". Ademais, o uso da estimativa tem destaque também nos Parâmetros Curriculares Nacionais, pois estes argumentam que "uma das finalidades atuais do ensino do cálculo consiste em fazer com que os alunos desenvolvam e sistematizem procedimentos de cálculo por estimativa e estratégias de verificação e controle de resultados" (Brasil, 1997, p. 77).

Os professores ainda expressaram algumas opiniões a respeito das atividades realizadas envolvendo estimativa. Seguem alguns dos depoimentos.

Notei que as crianças gostaram muito de realizar esta atividade, e que por eu ter dito que era uma brincadeira, eles ficaram ainda mais empolgados... (P10)

Foi um trabalho maravilhoso, quando questionados sobre estimativa, demorou um pouco para eles saber o que era, falaram informática, computador, matemática, números. Depois de falar para eles estimo que tenha 20 lápis naquela caixa que eles falaram que era adivinhar. (P18)

As crianças ficaram eufóricas com essa atividade. Cada qual queria dar primeiro a sua opinião. Com certeza foi um momento de aprendizagem muito válido. (P20)

Os educadores que exploraram atividades envolvendo o uso de estimativa foram unânimes em expressar o quanto os alunos ficaram interessados e relataram estratégias que, muitas vezes, os próprios professores não haviam pensado. Podemos inferir que o uso da estimativa nas aulas pode ser uma alternativa para desenvolver a motivação para a aprendizagem, a aquisição de competências de cálculos aproximados, bem como o desenvolvimento de tomar decisões por meio da sistematização de estratégias.
A partir da leitura dos relatórios, destacamos algumas colocações por parte dos participantes referentes à exploração das atividades realizadas durante o curso.

As atividades foram muito válidas para reforçar com os alunos que existem várias maneiras de se encontrar resultados e soluções, que podemos pensar diferente e chegar ao mesmo resultado, estando corretos também. (P7)

As aulas foram bem produtivas, os alunos permaneceram sempre bem aplicados e interessados nas realizações das atividades propostas. (P9)

No final acharam fácil estudar com Álgebra utilizando material concreto. Eu consegui explicar várias dúvidas deles, principalmente as operações com os números decimais e as operações com as frações. Os alunos gostaram da atividade. (P60)

Os alunos realizaram a atividade com interesse, ela foi muito proveitosa para resgatar algumas dúvidas dos alunos. Também foi interessante a realização deste trabalho em grupos, pois os alunos puderam trocar ideias de forma que um contribuiu para a construção do conhecimento do outro. Esse trabalho prático propicia um ambiente agradável e favorável para que o aluno estude com motivação e alegria. (P59)

Pelos excertos, notamos que os professores consideraram as aulas, nas quais desenvolveram as atividades propostas, muito produtivas, conforme apontado, por exemplo, em "realizaram [referindo-se aos alunos] a atividade com muito interesse". Assim, podemos inferir que as questões teórico-metodológicas tratadas na formação continuada podem adquirir novos significados para a prática em sala de aula na medida em que ampliam o 
conhecimento em relação aos conteúdos matemáticos e às formas de trabaIhá-los, "atribuindo significados à construção e apropriação da Matemática no processo do ensinar e do aprender" (Maccarini, 2007, p. 188).

Os docentes também expressaram que foi importante participar do curso de formação continuada, pois as atividades desenvolvidas os auxiliaram a (re) pensar e modificar a prática pedagógica.

A atividade foi muito envolvente, em geral todas as atividades aprendidas durante o Curso e aplicadas com a turma foram muito proveitosas. Avalio que o aprendizado foi muito importante para mim enquanto professora e também para eles enquanto alunos. Que bom que podemos sempre aprender mais! (P29)

Eu gostei muito de aplicar estas atividades, pois através delas, pude perceber algumas dificuldades dos meus alunos e espero através deste curso encontrar formas de poder ajudá-los e também poder esclarecer minhas dúvidas. (P18)

Participar deste curso fez-me refletir sobre a maneira de trabalhar Matemática, pois pouco trabalhava e hoje estou desafiada a fazer mais. Pude ver como meus alunos reagiam, experimentavam entusiasmados, interessados. Foi muito gratificante e pude perceber uma aprendizagem muito significativa. (P34)

O trabalho realizado foi muito envolvente e motivador para a turma. É gratificante despertar o interesse dos alunos pela Matemática. (P49)

Pelos excertos, deduzimos que os participantes consideraram as atividades desenvolvidas no decorrer do curso, além de produtivas, possíveis de serem trabalhadas em sala de aula. Ademais, o entusiasmo para com os resultados também ficou explícito em suas falas. Por tudo isso, inferimos que a formação continuada de docentes pode auxiliar a desenvolver conhecimento profissional que permita avaliar a necessidade de aperfeiçoamento e a qualidade de ensino que deve ser inserida nas escolas, desenvolvendo habilidades básicas do cotidiano; "proporcionando a aquisição de competências, transformando as atividades de ensino constantemente, adaptando na diversidade e ao contexto dos alunos" (Santos, 2011 , p. 24).

Em relação aos cursos, destacamos que a sistemática assumida nos cursos de formação - solicitar aos participantes que realizassem com seus alunos, no mínimo, duas atividades desenvolvidas - foi fundamental para que os conhecimentos adquiridos no curso fossem disseminados nas turmas em que estes docentes atuavam. No último encontro, muitos participantes comentaram que essa forma, inicialmente, trouxe receio; entretanto, após a exploração das atividades, o resultado foi produtivo.

Durante a socialização das atividades, os educadores expressaram que a troca de experiências possibilitou-lhes repensar a sua prática pedagógica. As perguntas dos colegas, os pedidos de esclarecimentos, as explicações do "porquê" se agiu desta ou daquela maneira levou-os à reflexão, conforme professor P37: "Com certeza usarei na minha prática docente, cada atividade 
desenvolvida no decorrer do curso, como também levarei as várias discussões e reflexões que aconteceram no transcorrer das manhãs desse curso, para aperfeiçoamento da minha prática pedagógica".

A seguir, destacamos algumas considerações que, ao não serem definitivas, apontam para a emergência de outros modos de pensar a formação continuada.

\section{Algumas considerações}

A discussão anteriormente empreendida permite destacar duas questões a serem analisadas. A primeira diz respeito à sistemática utilizada nos três cursos de formação aqui descritos. Em cada encontro, tivemos o intuito de proporcionar aos participantes aprimoramento profissional com situações reflexivas que possibilitassem modificar posturas, rever concepções, levando em conta seus conhecimentos e o contexto de atuação. Também, disponibilizamos aos participantes momentos para que pudessem expressar suas angústias, frustrações e sucessos. Observamos que esse tempo dedicado ao desabafo foi importante para o professor, pois era um espaço onde os colegas ouviam, trocavam ideias e refletiam sobre o assunto e a metodologia a ser adotada na prática pedagógica. Acreditamos, sobretudo, que isso possa ter contribuído para superar algumas inseguranças e dificuldades, bem como repensar a prática pedagógica dos participantes.
No que se refere ao conhecimento matemático, observamos que a alternância de discussões metodológicas e de conhecimentos específicos possibilitou que os professores confrontassem suas diferentes concepções que, a partir de reflexões, contribuíram para sua aprendizagem de conceitos matemáticos. Assim, podemos pensar que a formação continuada dos professores se apresenta como uma alternativa, uma vez que estes, quando em exercício, necessitam se atualizar para acompanhar os avanços da sociedade e, consequentemente, as mudanças no ensino de modo geral. Destacamos que a obrigatoriedade do desenvolvimento de, pelo menos duas atividades, durante o curso, e posterior escrita do relatório, foram determinantes para - aprofundamento das discussões e para a inserção de tais temáticas nas práticas pedagógicas.

A segunda questão a ser analisada refere-se à emergência de outros modos de concebermos cursos de formação. Diferentemente da concepção que preconiza a necessidade dos ministrantes proporcionar material instrucional a ser discutido nos encontros, seguimos pensando na possibilidade de os próprios participantes planejarem as atividades a serem problematizadas durante a formação continuada e sua posterior inserção nas práticas pedagógicas. Nesta ótica, ao grupo de pesquisadoras que propõe os cursos, caberiam apenas a tarefa de formar os grupos e de fomentar as referidas discussões.

\section{Referências bibliográficas}

Brasil. Secretaria de Educação Fundamental. (1997). Parâmetros curriculares nacionais: Matemática.

Primeiro e Segundo Ciclo. Secretaria de Educação Fundamental. Brasília: MEC/SEF.

Brasil. Ministério da Educação. (1998, abril). Parâmetros Curriculares Nacionais: matemática. Secretaria de Educação Fundamental. Recuperado em 25 abril, 2012, de http://portal.mec.gov. $\mathrm{br} / \mathrm{seb} /$ arquivos/pdf/matematica. pdf. 
Guérios, E. (2002). Espaços oficiais e intersticiais da formação docente: histórias de um grupo de professores na área de ciências e matemática. Tese de Doutorado, UNICAMP, Campinas, SP, Brasil.

Maccarini, J. I. (2007). Contribuições da formação continuada em Educação Matemática à prática do professor. Dissertação de (Mestrado em Educação) - Programa de Pós-Graduação em Educação, Universidade Tuiuti, Paraná, Curitiba, Paraná, Brasil.

Machado, I. A. (2010, junho). Algumas dificuldades do Ensino da Matemática na 7a série do Ensino Fundamental. Recuperado em 20 junho, 2012, de http://www. ucb.br/sites/100/103/TCC/12005/IveteAlvesMachado.pdf.

Mossmann, T. I. (2005). A formação continuada de professores na contemporaneidade: limites e possibilidades. Dissertação (Mestrado em Educação) - Programa de Pós-Graduação em Educação, Universidade Tuiuti do Paraná, Paraná, Curitiba, Brasil.

Romanowski, J. P. (2006). Formação e profissionalização docente. Curitiba: IBPEX.

Santos, M. P. (2011). Educação Continuada do Professor de Matemática: Uma Investigação sobre Grupo de Estudos no Coletivo Escolar. Dissertação de (Mestrado em Educação Matemática) - Programa de Pós-Graduação em Educação Matemática. Universidade Bandeirante de São Paulo, São Paulo, Brasil. 